\title{
Unique Fixed Point Theorems for Generalized Contractive Mappings in Partial Metric Spaces
}

\author{
Lakshmi Narayan Mishra, , ${ }^{1,2}$ Shiv Kant Tiwari, ${ }^{3}$ \\ Vishnu Narayan Mishra, ${ }^{4}$ and Idrees A. Khan ${ }^{5}$ \\ ${ }^{1}$ Department of Mathematics, National Institute of Technology, Silchar, Cachar, Assam 788 010, India \\ ${ }^{2}$ L. 1627 Awadh Puri Colony Beniganj, Phase-III, Opposite-Industrial Training Institute (I.T.I.), Ayodhya Main Road, \\ Faizabad, Uttar Pradesh 224 001, India \\ ${ }^{3}$ Department of Applied Mathematics, University Institute of Technology, Rajiv Gandhi Technical University, \\ Bhopal, Madhya Pradesh 462 033, India \\ ${ }^{4}$ Department of Applied Mathematics and Humanities, Sardar Vallabhbhai National Institute of Technology, \\ Ichchhanath Mahadev Dumas Road, Surat, Gujarat 395 007, India \\ ${ }^{5}$ Department of Mathematics, Integral University, Lucknow, Uttar Pradesh 226 026, India
}

Correspondence should be addressed to Lakshmi Narayan Mishra; lakshminarayanmishra04@gmail.com

Received 8 August 2014; Accepted 25 September 2014

Academic Editor: Mohammad Mursaleen

Copyright (C) 2015 Lakshmi Narayan Mishra et al. This is an open access article distributed under the Creative Commons Attribution License, which permits unrestricted use, distribution, and reproduction in any medium, provided the original work is properly cited.

We establish some unique fixed point theorems in complete partial metric spaces for generalized weakly $S$-contractive mappings, containing two altering distance functions under certain assumptions. Also, we discuss some examples in support of our main results.

\section{Introduction and Preliminaries}

An abstract metric space was first introduced and studied by the French mathematician Frechet [1] in 1906. Many researchers have generalized the concept of metric space as cone metric space, semimetric space, quasimetric space, and so forth, along with the generalization of contraction mappings with applications (see [2-7]). The best approximations of functions in locally convex spaces were discussed by Mishra et al. [8] and Mishra [9]. The degree of approximation of signals in Lp-space is established in [10].

Matthews [11, 12] initiated the concept of partial metric space as another generalization of metric space to study the denotational semantics of dataflow networks. Also, Matthews [11] generalized the Banach contraction principle to the class of partial metric spaces as follows: let $(X, p)$ be a complete partial metric space, and then a self-mapping $T$ on $X$, satisfying

$$
p(T x, T y) \leq k p(x, y) \quad \forall x, y \in X,
$$

where $0 \leq k<1$, has a unique fixed point.
After the Matthews [11] historical contribution, several researchers have established some more fixed point theorems in partial metric spaces and also discussed its topological properties (see [13-15] and references therein).

First, we recall some useful definitions and results, which is useful throughout the paper.

Definition 1 (see [11, 12]). Let $X$ be a nonempty set, and a mapping $p: X \times X \rightarrow[0, \infty)$ satisfying the following conditions is called a partial metric space on $X$ :

$$
\begin{aligned}
& \left(P_{1}\right) p(x, y)=p(y, x), \\
& \left(P_{2}\right) p(x, x)=p(x, y)=p(y, y) \Leftrightarrow x=y, \\
& \left(P_{3}\right) p(x, x) \leq p(x, y), \\
& \left(P_{4}\right) p(x, y) \leq p(x, z)+p(z, y)-p(z, z),
\end{aligned}
$$

for all $x, y, z \in X$, and the pair $(X, p)$ is called a partial metric space. In the rest of the paper, $(X, p)$ represents a partial metric space equipped with a partial metric $p$, unless 
otherwise stated. Let $(X, p)$ be a partial metric space and then let a function $d^{p}: X \times X \rightarrow[0, \infty)$ be defined as

$$
d^{p}(x, y)=2 p(x, y)-p(y, y)-p(x, x)
$$

which is a metric on $X$. Consider the function $d^{m}: X \times X \rightarrow$ $[0, \infty)$ such that

$$
\begin{aligned}
d^{m}(x, y) & =\max \{p(x, y)-p(x, x), p(x, y)-p(y, y)\} \\
& =p(x, y)-\min \{p(x, x), p(y, y)\}
\end{aligned}
$$

then $d^{m}$ is a metric on $X$, and both of the above metrics $d^{p}$ and $d^{m}$ are equivalent [16].

Remark 2 (see [17]). In a partial metric space $(X, p)$,

(1) $p(x, y)=0 \Rightarrow x=y$ but if $x=y$, then $p(x, y)$ may not be zero,

(2) $p(x, y)>0$ for all $x \neq y$,

for all $x, y \in X$.

Example 3 (see [16]). Consider a mapping $p:[0, \infty) \times$ $[0, \infty) \rightarrow[0, \infty)$ such that $p(x, y)=\max \{x, y\}$ for all $x, y \in[0, \infty)$. Then $p$ will satisfy all the property of partial metric, and hence $([0, \infty), p)$ is a partial metric space but fails to be the condition of $p(x, x)=0$ for all nonzero $x \in[0, \infty)$. Therefore $([0, \infty), p)$ is not a metric space.

Example 4 (see $[16,18])$. Let $p_{i}: X \times X \rightarrow[0, \infty)(i=1,2,3)$ be three mappings and for any arbitrary mapping $f: X \rightarrow$ $[0, \infty)$ such that

$$
\begin{aligned}
& p_{1}(x, y)=d(x, y)+p(x, y), \\
& p_{2}(x, y)=d(x, y)+\max \{f(x), f(y)\}, \\
& p_{3}(x, y)=d(x, y)+r
\end{aligned}
$$

for all $r \geq 0$, where $(X, d)$ and $(X, p)$ are a metric space and a partial metric space, respectively. Then each $p_{i}$ is the partial metric on $X$.

Definition 5 (see [19]). In a partial metric space $(X, p),(1)$ a sequence $\left\{x_{n}\right\}$ is said to be convergent to a point $x \in X$ if and only if $\lim _{n \rightarrow \infty} p\left(x_{n}, x\right)=p(x, x)$.

(2) A sequence $\left\{x_{n}\right\}$ is called Cauchy sequence if and only if $\lim _{n, m \rightarrow \infty} p\left(x_{n}, x_{m}\right)$ is finite.

(3) If every Cauchy sequence $\left\{x_{n}\right\}$ converges to a point $x \in X$ such that

$$
\lim _{n, m \rightarrow \infty} p\left(x_{n}, x_{m}\right)=p(x, x)
$$

then $(X, p)$ is known as complete partial metric space.

Definition 6 (see $[20,21])$. A self-mapping $\psi$ on a positive real number is said to be an altering distance function, if it holds for all $t \in[0, \infty)$ such that

(1) $\psi$ is continuous and nondecreasing,

(2) $\psi(t)=0 \Leftrightarrow t=0$.
The generalization of contractive mappings into $C$ contractive mappings has been introduced by Chatterjea [6].

Definition 7 (see $[2,21])$. A self-mapping $T$ on a metric space $(X, d)$, satisfying

$$
\begin{aligned}
d(T x, T y) \leq & \frac{1}{2}[d(x, T y)+d(T x, y)] \\
& -\phi(d(x, T y), d(T x, y)),
\end{aligned}
$$

for all $x, y \in X$ and $\phi:[0, \infty)^{2} \rightarrow[0, \infty)$ is a continuous mapping with $\phi(x, y)=0$ if and only if $x=y=0$ is called weakly $C$-contractive mapping or a weak $C$-contraction.

Shukla and Tiwari [3] have introduced the concept of weakly $S$-contractive mappings.

Definition 8 (see [3]). A self-mapping $T$ on a complete metric space $(X, d)$ is said to be weakly $S$-contractive mapping or a weak $S$-contraction, if the following inequality holds:

$$
\begin{aligned}
d(T x, T y) \leq & \frac{1}{3}[d(x, T y)+d(T x, y)+d(x, y)] \\
& -\phi(d(x, T y), d(T x, y), d(x, y)),
\end{aligned}
$$

for all $x, y \in X$ and $\phi:[0, \infty)^{3} \rightarrow[0, \infty)$ is a continuous function with $\phi(x, y, z)=0$ if and only if $x=y=z=0$.

Lemma 9 (see $[7,14]$ ). In a partial metric space $(X, p)$, if a sequence $\left\{x_{n}\right\}$ is convergent to a point $x \in X$, then $\lim _{n \rightarrow \infty} p\left(x_{n}, x\right) \leq p(x, z)$ for all $z \in X$. Also, if $p(x, x)=0$, then

$$
\lim _{n \rightarrow \infty} p\left(x_{n}, z\right)=p(x, z) \quad \forall z \in X .
$$

Lemma 10 (see [13]). If $\left\{x_{2 n}\right\}$ is not a Cauchy sequence in $(X, p)$ and two sequences $\{m(k)\}$ and $\{n(k)\}$ of positive integers such that $n(k)>m(k)>k$, then the four sequences

$$
\begin{gathered}
p\left(x_{2 m(k)}, x_{2 n(k)+1}\right), p\left(x_{2 m(k)}, x_{2 n(k)}\right), \\
p\left(x_{2 m(k)-1}, x_{2 n(k)+1}\right), p\left(x_{2 m(k)-1}, x_{2 n(k)}\right)
\end{gathered}
$$

tend to $\varepsilon>0$, when $k \rightarrow \infty$.

Lemma 11 (see $[13,16])$. In a partial metric space $(X, p)$ :

(1) a sequence $\left\{x_{n}\right\}$ is a Cauchy if and only if it is a Cauchy in $\left(X, d^{p}\right)$,

(2) $X$ is complete if and only if it is complete in $\left(X, d^{p}\right)$.

In addition, $\lim _{n \rightarrow \infty} d^{P}\left(x_{n}, x\right)=0$ if and only if

$$
\lim _{n, m \rightarrow \infty} p\left(x_{n}, x_{m}\right)=\lim _{n \rightarrow \infty} p\left(x_{n}, x\right)=p(x, x) .
$$

If $\left\{x_{n}\right\}$ is a Cauchy sequence in the metric space $\left(X, d^{p}\right)$, we have

$$
\lim _{n, m \rightarrow \infty} d^{p}\left(x_{n}, x_{m}\right)=0
$$

and therefore, by definition of $d^{p}$, we have

$$
\lim _{n, m \rightarrow \infty} p\left(x_{n}, x_{m}\right)=0 \text {. }
$$




\section{Main Results}

Theorem 12. Let $(X, p)$ be a complete partial metric space and $\psi$ and $\varphi$ be two altering distance functions such that $\psi(t)-\varphi(t) \geq 0 \forall t \geq 0$. Then the self-continuous nondecreasing mapping $T$ on $X$, satisfying the condition

$$
\begin{aligned}
\psi(p(T x, T y)) \leq & \varphi\left(\frac{p(x, T y)+p(T x, y)+p(x, y)}{3}\right) \\
& -\phi(p(x, T y), p(T x, y), p(x, y)),
\end{aligned}
$$

for all $x, y \in X$ and $\phi:[0, \infty)^{3} \rightarrow[0, \infty)$ is a continuous function such that $\phi(x, y, z)=0$ if and only if $x=y=z=0$, has a unique fixed point in $X$.

Proof. First we prove that if fixed point of $T$ exists, then it will be unique. On the contrary, we consider two fixed points $z, u \in X$ of $T$ such that $z \neq u$. Then by (12), we have

$$
\begin{aligned}
\psi(p(z, u))= & \psi(p(T z, T u)) \\
\leq & \varphi\left(\frac{p(z, T u)+p(T z, u)+p(z, u)}{3}\right) \\
& -\phi(p(z, T u), p(T z, u), p(z, u)) \\
\Longrightarrow & 0 \leq(\psi-\varphi)(p(z, u)) \\
\leq & -\phi(p(z, u), p(z, u), p(z, u)) .
\end{aligned}
$$

By the property of $\phi$, we obtain

$$
\phi(p(z, u), p(z, u), p(z, u))=0 \Longrightarrow p(z, u)=0 .
$$

Using Remark 2, we obtain $z=u$, which is a contradiction with respect to $z \neq u$. Thus, we conclude that $T$ has a unique fixed point in $X$.

Next, we show that the mappings $T$, satisfying (12), have a fixed point. We choose an arbitrary point $x_{0}$ in $X$. If $x_{0}=T x_{0}$, then the theorem follows trivially. Now, we suppose that $x_{0} \leq$ $T x_{0}$ and we choose $x_{1} \in X$ such that $T x_{0}=x_{1}$. Since $T$ is a nondecreasing function, then we have $x_{0} \leq x_{1}=T x_{0} \leq T x_{1}$. Again, let $x_{2}=T x_{1}$. Then we get

$$
x_{0} \leq x_{1}=T x_{0} \leq T x_{1}=x_{2} \leq T x_{2} .
$$

Proceeding with this work, we obtained a sequence $\left\{x_{n}\right\}$ in $X$ such that $x_{n+1}=T x_{n}$ and

$$
x_{0} \leq x_{1} \leq x_{2} \leq x_{3} \leq \cdots \leq x_{n} \leq x_{n+1} \cdots .
$$

Supposing that $p\left(x_{n_{0}}, x_{n_{0}+1}\right)=0$ for some $n_{0} \geq 0$, then by Remark 2 we have

$$
x_{n_{0}}=x_{n_{0}+1}=T x_{n_{0}}, \quad \text { that is, } x_{n_{0}} \text { is a fixed point of } T \text {. }
$$

Again, we suppose that $p\left(x_{2 n}, x_{2 n+1}\right)>0 \forall n \geq 0$. Firstly, we prove that the sequence $\left\{p\left(x_{2 n}, x_{2 n+1}\right)\right\}$ is nonincreasing. Suppose this is not true, and then

$$
p\left(x_{2 n}, x_{2 n+1}\right) \geq p\left(x_{2 n-1}, x_{2 n}\right) \quad \forall n \geq 0 .
$$

Putting $x=x_{2 n-1}$ and $y=x_{2 n}$ in (12) and using $\left(P_{4}\right)$, we have

$$
\begin{aligned}
\psi( & \left.\left(x_{2 n}, x_{2 n+1}\right)\right) \\
= & \psi\left(p\left(T x_{2 n-1}, T x_{2 n}\right)\right) \\
\leq & \varphi\left(\frac{p\left(x_{2 n-1}, T x_{2 n}\right)+p\left(T x_{2 n-1}, x_{2 n}\right)+p\left(x_{2 n-1}, x_{2 n}\right)}{3}\right) \\
& -\phi\left(p\left(x_{2 n-1}, T x_{2 n}\right), p\left(T x_{2 n-1}, x_{2 n}\right), p\left(x_{2 n-1}, x_{2 n}\right)\right) .
\end{aligned}
$$

Using $\left(P_{4}\right)$ above, we get

$$
\begin{aligned}
& \psi\left(p\left(x_{2 n}, x_{2 n+1}\right)\right) \\
& \leq \varphi\left(\frac{2 p\left(x_{2 n-1}, x_{2 n}\right)+p\left(x_{2 n}, x_{2 n+1}\right)}{3}\right) \\
& \quad-\phi\left(p\left(x_{2 n-1}, x_{2 n+1}\right), p\left(x_{2 n}, x_{2 n}\right), p\left(x_{2 n-1}, x_{2 n}\right)\right) .
\end{aligned}
$$

Using (18) above, we have

$$
\begin{aligned}
0 \leq & (\psi-\varphi)\left(p\left(x_{2 n}, x_{2 n+1}\right)\right) \\
\leq & -\phi\left(p\left(x_{2 n-1}, x_{2 n+1}\right), p\left(x_{2 n}, x_{2 n}\right), p\left(x_{2 n-1}, x_{2 n}\right)\right) . \\
\Longrightarrow & \phi\left(p\left(x_{2 n-1}, x_{2 n+1}\right), p\left(x_{2 n}, x_{2 n}\right), p\left(x_{2 n-1}, x_{2 n}\right)\right)=0 \\
\Longrightarrow & p\left(x_{2 n-1}, x_{2 n+1}\right)=0, \quad p\left(x_{2 n}, x_{2 n}\right)=0, \\
& p\left(x_{2 n-1}, x_{2 n}\right)=0 \\
\quad \forall n \geq 0 & \\
\Longrightarrow & p\left(x_{2 n}, x_{2 n+1}\right)=0 \quad \forall n \geq 0,
\end{aligned}
$$

which contradicts our assumption that $p\left(x_{2 n-1}, x_{2 n+1}\right)>0$ for all $n \geq 0$. Thus, we deduce that $\left\{p\left(x_{2 n}, x_{2 n+1}\right)\right\}$ is a nonincreasing sequence. Therefore

$$
p\left(x_{2 n}, x_{2 n+1}\right) \leq p\left(x_{2 n-1}, x_{2 n}\right) \quad \forall n \geq 0 .
$$

Since $\left\{p\left(x_{2 n}, x_{2 n+1}\right)\right\}$ is a monotonically decreasing and bounded below sequence in $X$, then there exists $r \geq 0$ such that

$$
\lim _{n \rightarrow \infty} p\left(x_{2 n}, x_{2 n+1}\right)=r .
$$

Using (23) and letting $n \rightarrow \infty$ in (20), we get

$$
\begin{aligned}
0 \leq & (\psi-\varphi)(r) \\
\leq & -\phi\left(\lim _{n \rightarrow \infty} p\left(x_{2 n-1}, x_{2 n+1}\right), \lim _{n \rightarrow \infty} p\left(x_{2 n}, x_{2 n}\right), r\right) \\
\Longrightarrow & \phi\left(\lim _{n \rightarrow \infty} p\left(x_{2 n-1}, x_{2 n+1}\right), \lim _{n \rightarrow \infty} p\left(x_{2 n}, x_{2 n}\right), r\right)=0 \\
\Longrightarrow & \lim _{n \rightarrow \infty} p\left(x_{2 n-1}, x_{2 n+1}\right)=0, \\
& \lim _{n \rightarrow \infty} p\left(x_{2 n}, x_{2 n}\right)=0, \quad r=0 .
\end{aligned}
$$


Then (23) reduces to

$$
\lim _{n \rightarrow \infty} p\left(x_{2 n}, x_{2 n+1}\right)=0 \quad \forall n \geq 0 .
$$

Now, we have required proving that the sequence $\left\{x_{n}\right\}$ is a Cauchy sequence in the metric space $\left(X, d^{p}\right)$ and so in $(X, p)$ by Lemma 11. On the contrary, that is, the sequence $\left\{x_{2 n}\right\}$ not being a Cauchy sequence in $\left(X, d^{P}\right)$, sequences in Lemma 10 tend to $\varepsilon$, when $k \rightarrow \infty$. Now, we put $x=x_{2 n(k)+1}$ and $y=$ $x_{2 m(k)}$ in (12). We have

$$
\begin{gathered}
\psi\left(p\left(x_{2 n(k)+1}, x_{2 m(k)}\right)\right) \\
=\psi\left(p\left(T x_{2 n(k)}, T x_{2 m(k)-1}\right)\right) \\
\leq \varphi\left(\left(p\left(x_{2 n(k)}, T x_{2 m(k)-1}\right)+p\left(T x_{2 n(k)}, x_{2 m(k)-1}\right)\right.\right. \\
\left.\left.+p\left(x_{2 n(k)}, x_{2 m(k)-1}\right)\right)(3)^{-1}\right) \\
-\phi\left(p\left(x_{2 n(k)}, T x_{2 m(k)-1}\right), p\left(T x_{2 n(k)}, x_{2 m(k)-1}\right),\right. \\
\left.\quad p\left(x_{2 n(k)}, x_{2 m(k)-1}\right)\right) \\
=\varphi\left(\left(p\left(x_{2 n(k)}, x_{2 m(k)}\right)+p\left(x_{2 n(k)+1}, x_{2 m(k)-1}\right)\right.\right. \\
\left.\left.+p\left(x_{2 n(k)}, x_{2 m(k)-1}\right)\right)(3)^{-1}\right) \\
-\phi\left(p\left(x_{2 n(k)}, x_{2 m(k)}\right), p\left(x_{2 n(k)+1}, x_{2 m(k)-1}\right),\right. \\
\left.p\left(x_{2 n(k)}, x_{2 m(k)-1}\right)\right) .
\end{gathered}
$$

Taking $k \rightarrow \infty$ and applying Lemma 10 in the above inequality, we have

$$
\begin{aligned}
0 & \leq(\psi-\varphi)(\varepsilon) \leq-\phi(\varepsilon, \varepsilon, \varepsilon) \\
\Longrightarrow \phi(\varepsilon, \varepsilon, \varepsilon) & =0 \Longrightarrow \varepsilon=0,
\end{aligned}
$$

which is a contradiction with respect to $\varepsilon>0$. Thus $\left\{x_{2 n}\right\}$ is a Cauchy sequence in $\left(X, d^{p}\right)$ and so in $(X, p)$. Since $(X, p)$ is complete, $\left(X, d^{p}\right)$ is also complete (by Lemma 11). Therefore, the Cauchy sequence $\left\{x_{n}\right\}$ converges in $\left(X, d^{P}\right)$; that is, $\lim _{n \rightarrow \infty} d^{P}\left(x_{n}, z\right)=0$; then by Lemma 11, we have

$$
p(z, z)=\lim _{n \rightarrow \infty} p\left(x_{n}, z\right)=\lim _{n, m \rightarrow \infty} p\left(x_{n}, x_{m}\right) \text {. }
$$

By Lemma 11, we get $\lim _{n, m \rightarrow \infty} d^{p}\left(x_{n}, x_{m}\right)=0$. So, by definition of $d^{p}$, we get

$$
d^{p}\left(x_{n}, x_{m}\right)=2 p\left(x_{n}, x_{m}\right)-p\left(x_{n}, x_{n}\right)-p\left(x_{m}, x_{m}\right) .
$$

Using (24) and taking $n, m \rightarrow \infty$ in the above inequality, we obtain

$$
\lim _{n, m \rightarrow \infty} p\left(x_{n}, x_{m}\right)=0 .
$$

From (28) and (30), we get

$$
p(z, z)=\lim _{n \rightarrow \infty} p\left(x_{n}, z\right)=0 .
$$

By $\left(P_{4}\right)$, we obtain

$$
p(z, T z) \leq p\left(z, x_{n}\right)+p\left(x_{n}, T z\right)-p\left(x_{n}, x_{n}\right) .
$$

Taking $n \rightarrow \infty$ and using (31), (24), and Lemma 9 in the above inequality, we have

$$
p(z, T z) \leq p(T z, T z) .
$$

From $\left(P_{2}\right)$, we have

$$
p(T z, T z) \leq p(z, T z) .
$$

By (33) and (34), we get

$$
p(z, T z)=p(T z, T z) .
$$

From (35) and (12), we obtain

$$
\begin{aligned}
\psi(p(z, T z))= & \psi(p(T z, T z)) \\
\leq & \varphi\left(\frac{p(z, T z)+p(T z, z)+p(z, z)}{3}\right) \\
& -\phi(p(z, T z), p(T z, z), p(z, z)) .
\end{aligned}
$$

Using (31) and property of $\varphi$ in the above inequality, we obtain

$$
\begin{aligned}
0 & \leq(\psi-\varphi) p(z, T z) \leq-\phi(p(z, T z), p(T z, z), 0) \\
& \Longrightarrow \phi(p(z, T z), p(T z, z), 0)=0 \Longrightarrow p(z, T z)=0 \\
& \Longrightarrow T z=z .
\end{aligned}
$$

Thus, $z$ is a unique fixed point of $T$ in $X$.

Example 13. Let $([0,1], p)$ be a complete partial metric space defined by $p(x, y)=\max \{x, y\} \forall x, y \in[0,1]$. Consider a self-map $T$ on $[0,1]$ such that $T x=3 x^{2}+2 x^{3}$. Also, we define $\psi, \varphi:[0, \infty) \rightarrow[0, \infty)$ such that $\psi(t)=t+t^{2} / 2, \varphi(t)=$ $3 t^{2}+t^{3}$, respectively, and $\phi:[0, \infty)^{3} \rightarrow[0, \infty)$ such that $\phi(p, q, r)=(p+q+r)^{2} / 54$.

If $x \geq y$, then

$$
\begin{gathered}
p(T x, T y)=\max \{T x, T y\}=T x=3 x^{2}+2 x^{3}, \\
\psi(p(T x, T y))=3 x^{2}+2 x^{3}+\frac{9}{2} x^{4}+6 x^{5}+2 x^{6}, \\
\varphi\left(\frac{p(x, y)+p(T x, y)+p(x, T y)}{3}\right) \\
=\left(2 x+3 x^{2}+2 x^{3}\right)^{2}\left(3+2 x+3 x^{2}+2 x^{3}\right) \\
\phi(p(x, y), p(T x, y), p(x, T y))=\frac{\left(2 x+3 x^{2}+2 x^{3}\right)^{2}}{54} .
\end{gathered}
$$

We observe that, for all $x, y \in[0,1]$,

$$
\begin{aligned}
\psi(p(T x, T y)) \leq & \varphi\left(\frac{p(x, y)+p(T x, y)+p(x, T y)}{3}\right) \\
& -\phi(p(x, y), p(T x, y), p(x, T y)) .
\end{aligned}
$$

Similarly, we can show the result for $y \geq x$. Thus, (12) holds for all $x, y \in[0,1]$ and satisfies all the requirements of Theorem 12. So, 0 is the unique fixed point of $T$. 
Corollary 14. Let $(X, p)$ be a complete partial metric space. Then the self-continuous nondecreasing mapping $T$ on $X$, satisfying the condition

$$
\begin{aligned}
\psi(p(T x, T y)) \leq & \psi\left(\frac{p(x, T y)+p(T x, y)+p(x, y)}{3}\right) \\
& -\phi(p(x, T y), p(T x, y), p(x, y))
\end{aligned}
$$

for all $x, y \in X$ and $\psi$ and $\phi$ which are the same as in Theorem 12, has a unique fixed point in $X$.

Corollary 15. In Corollary 14, if partial metric space $(X, p)$ is replaced by usual metric space $(X, d)$, then it reduces to the result of [21].

Corollary 16. In Theorem 12, if we take $\psi(t)=\phi(t)=t$ and partial metric space $(X, p)$ is replaced by usual metric space $(X, d)$, then we obtain the main result of [3], which unifies the main result of [2].

Corollary 17. If we put $p(x, y)=0$ in (12) and let $\phi:[0, \infty) \times$ $[0, \infty) \rightarrow[0, \infty)$ be a function, such that $\phi(x, y)=0$ if and only if $x=y=0$, then Theorem 12 reduces to Theorem 2.1 of [13].

Theorem 18. Let $(X, p)$ be a complete partial metric space and $\psi$ and $\varphi$ be two altering distance functions such that $\psi(t)-$ $\varphi(t) \geq 0 \forall t \geq 0$. Then the two self-continuous nondecreasing mappings $S$ and $T$ on $X$, satisfying the condition

$$
\begin{aligned}
\psi(p(T x, S y)) \leq & \varphi\left(\frac{p(x, S y)+p(T x, y)+p(x, y)}{3}\right) \\
& -\phi(p(x, S y), p(T x, y), p(x, y))
\end{aligned}
$$

for all $x, y \in X$ and $\phi:[0, \infty)^{3} \rightarrow[0, \infty)$ is a continuous function such that $\phi(x, y, z)=0$ if and only if $x=y=z=0$, having a unique common fixed point in $X$.

Proof. First, we show that the common fixed point of $T$ and $S$ is unique, if it exists. On the contrary, we assume two common fixed points $z, u \in X$ of $T$ and $S$ such that $z \neq u$. Then by (41), we get

$$
\begin{aligned}
\psi(p(z, u))= & \psi(p(T z, S u)) \\
\leq & \varphi\left(\frac{p(z, S u)+p(T z, u)+p(z, u)}{3}\right) \\
& -\phi(p(z, S u), p(T z, u), p(z, u)) \\
\Longrightarrow & 0 \leq(\psi-\varphi)(p(z, u)) \\
\leq & -\phi(p(z, u), p(z, u), p(z, u)) .
\end{aligned}
$$

Property of $\phi$ implies that

$$
\phi(p(z, u), p(z, u), p(z, u))=0 \Longrightarrow p(z, u)=0 \Longrightarrow z=u,
$$

which contradicts our assumption that $u \neq z$. Therefore, we conclude that $T$ and $S$ have a unique common fixed point in $X$.

Now, we prove that the mappings $S$ and $T$, satisfying (41), have a common fixed point in $X$. We choose an arbitrary point $x_{0}$ in $X$. If $x_{0}=S x_{0}$ and $x_{0}=T x_{0}$, then theorem follows trivially. So, we suppose that $x_{0} \neq S x_{0}$ and $x_{0} \neq T x_{0}$. Then we construct a sequence $\left\{x_{n}\right\}$ in $X$, in such a way that $S x_{2 n+1}=x_{2 n+2}$ and $T x_{2 n}=x_{2 n+1} \quad \forall n \geq 0$.

Let us assume that $p\left(x_{2 n}, x_{2 n+1}\right)>0$ and $p\left(x_{2 n}, x_{2 n+2}\right)>$ $0 \forall n \geq 0$. Then, we can prove that $S$ and $T$ have a common fixed point in $X$. Firstly, we show that $\left\{p\left(x_{2 n}, x_{2 n+1}\right)\right\}$ is nonincreasing sequence. Suppose this is not true, and then

$$
p\left(x_{2 n}, x_{2 n+1}\right) \geq p\left(x_{2 n-1}, x_{2 n}\right) \quad \forall n \geq 0 .
$$

Putting $x=x_{2 n}$ and $y=x_{2 n+1}$ in (41) and using $\left(P_{4}\right)$, we get

$$
\begin{aligned}
\psi & \left(p\left(x_{2 n+1}, x_{2 n+2}\right)\right) \\
= & \psi\left(p\left(T x_{2 n}, S x_{2 n+1}\right)\right) \\
\leq & \varphi\left(\frac{p\left(x_{2 n}, S x_{2 n+1}\right)+p\left(T x_{2 n}, x_{2 n+1}\right)+p\left(x_{2 n}, x_{2 n+1}\right)}{3}\right) \\
& -\phi\left(p\left(x_{2 n}, S x_{2 n+1}\right), p\left(T x_{2 n}, x_{2 n+1}\right), p\left(x_{2 n}, x_{2 n+1}\right)\right) .
\end{aligned}
$$

Using $\left(P_{4}\right)$ above, we get

$$
\begin{aligned}
& \psi\left(p\left(x_{2 n+1}, x_{2 n+2}\right)\right) \\
& \leq \varphi\left(\frac{2 p\left(x_{2 n}, x_{2 n+1}\right)+p\left(x_{2 n+1}, x_{2 n+2}\right)}{3}\right) \\
& \quad-\phi\left(p\left(x_{2 n}, x_{2 n+2}\right), p\left(x_{2 n+1}, x_{2 n+1}\right), p\left(x_{2 n}, x_{2 n+1}\right)\right) .
\end{aligned}
$$

By (44) and (46), we obtain

$$
\begin{gathered}
0 \leq(\psi-\varphi)\left(p\left(x_{2 n+1}, x_{2 n+2}\right)\right) \\
\leq-\phi\left(p\left(x_{2 n}, x_{2 n+2}\right), p\left(x_{2 n+1}, x_{2 n+1}\right), p\left(x_{2 n}, x_{2 n+1}\right)\right) \\
\Longrightarrow \phi\left(p\left(x_{2 n}, x_{2 n+2}\right), p\left(x_{2 n+1}, x_{2 n+1}\right), p\left(x_{2 n}, x_{2 n+1}\right)\right)=0 \\
\Longrightarrow p\left(x_{2 n+1}, x_{2 n+1}\right)=0, \quad p\left(x_{2 n}, x_{2 n+1}\right)=0, \\
p\left(x_{2 n}, x_{2 n+2}\right)=0 \\
\forall n \geq 0,
\end{gathered}
$$

which is a contradiction with respect to $p\left(x_{2 n}, x_{2 n+1}\right)>0$ and $p\left(x_{2 n}, x_{2 n+2}\right)>0 \forall n \geq 0$. Therefore $\left\{p\left(x_{2 n}, x_{2 n+1}\right)\right\}$ is a nonincreasing sequence in $X$. Thus, we have

$$
p\left(x_{2 n}, x_{2 n+1}\right) \leq p\left(x_{2 n-1}, x_{2 n}\right) \quad \forall n \geq 0 .
$$

Since $\left\{p\left(x_{2 n}, x_{2 n+1}\right)\right\}$ is a monotonically decreasing sequence in $X$, then there exists $r \geq 0$ such that

$$
\lim _{n \rightarrow \infty} p\left(x_{2 n}, x_{2 n+1}\right)=r \text {. }
$$


Letting $n \rightarrow \infty$ in (46) and using (49), consequently we get

$$
\begin{aligned}
0 & \leq(\psi-\varphi)(r) \\
& \leq-\phi\left(\lim _{n \rightarrow \infty} p\left(x_{2 n}, x_{2 n+2}\right), \lim _{n \rightarrow \infty} p\left(x_{2 n+1}, x_{2 n+1}\right), r\right) \\
& \Longrightarrow \phi\left(\lim _{n \rightarrow \infty} p\left(x_{2 n}, x_{2 n+2}\right), \lim _{n \rightarrow \infty} p\left(x_{2 n+1}, x_{2 n+1}\right), r\right)=0 \\
& \Longrightarrow \lim _{n \rightarrow \infty} p\left(x_{2 n}, x_{2 n+2}\right)=0, \lim _{n \rightarrow \infty} p\left(x_{2 n+1}, x_{2 n+1}\right)=0, r=0 .
\end{aligned}
$$

Then (49) will get reduced to

$$
\lim _{n \rightarrow \infty} p\left(x_{2 n}, x_{2 n+1}\right)=r=0 \quad \forall n \geq 0 .
$$

Now, we have to show that $\left\{x_{n}\right\}$ is a Cauchy sequence in the partial metric space $(X, p)$. By similar arguments as used in case of proving Theorem 12 we find that the sequence $\left\{x_{2 n}\right\}$ is a Cauchy sequence. Putting $x=x_{2 n(k)}$ and $y=x_{2 m(k)-1}$ in (41), we have

$$
\begin{gathered}
\psi\left(p\left(x_{2 n(k)+1}, x_{2 m(k)}\right)\right) \\
=\psi\left(p\left(T x_{2 n(k)}, S x_{2 m(k)-1}\right)\right) \\
\leq \varphi\left(\left(p\left(x_{2 n(k)}, S x_{2 m(k)-1}\right)+p\left(T x_{2 n(k)}, x_{2 m(k)-1}\right)\right.\right. \\
\left.\left.+p\left(x_{2 n(k)}, x_{2 m(k)-1}\right)\right)(3)^{-1}\right) \\
-\phi\left(p\left(x_{2 n(k)}, S x_{2 m(k)-1}\right), p\left(T x_{2 n(k)}, x_{2 m(k)-1}\right),\right. \\
\left.p\left(x_{2 n(k)}, x_{2 m(k)-1}\right)\right) .
\end{gathered}
$$

Taking $k \rightarrow \infty$ and using Lemma 10 in the above inequality, we obtain

$$
0 \leq(\psi-\varphi)(\varepsilon) \leq-\phi(\varepsilon, \varepsilon, \varepsilon) \Longrightarrow \phi(\varepsilon, \varepsilon, \varepsilon)=0 \Longrightarrow \varepsilon=0
$$

which contradicts our assumption that $\varepsilon>0$. Thus $\left\{x_{2 n}\right\}$ is a Cauchy sequence in $\left(X, d^{p}\right)$ and so in $(X, p)$. Further, by similar arguments of Theorem 12, we obtain

$$
p(z, z)=\lim _{n \rightarrow \infty} p\left(x_{n}, z\right)=\lim _{n, m \rightarrow \infty} p\left(x_{n}, x_{m}\right)=0 .
$$

By substituting $x=z, y=x_{2 m(k)-1}$ in (41), we obtain

$$
\begin{gathered}
\psi\left(p\left(T z, x_{2 m(k)}\right)\right) \\
=\psi\left(p\left(T z, S x_{2 m(k)-1}\right)\right) \\
\leq \varphi\left(\left(p\left(z, S x_{2 m(k)-1}\right)+p\left(T z, x_{2 m(k)-1}\right)\right.\right. \\
\left.\left.+p\left(z, x_{2 m(k)-1}\right)\right)(3)^{-1}\right) \\
-\phi\left(p\left(z, S x_{2 m(k)-1}\right), p\left(T z, x_{2 m(k)-1}\right),\right. \\
\left.p\left(z, x_{2 m(k)-1}\right)\right) .
\end{gathered}
$$

Letting $k \rightarrow \infty$ and using (54) with property of nondecreasing function $\varphi$ in the above inequality, we obtain

$$
\begin{aligned}
0 & \leq(\psi-\varphi) p(T z, z) \leq-\phi(p(0, p(T z, z), 0)) \\
& \Longrightarrow \phi(0, p(T z, z), 0)=0 \Longrightarrow p(z, T z)=0 \\
& \Longrightarrow T z=z .
\end{aligned}
$$

Hence $z$ is a fixed point of T. Similarly, if we take $x=x_{2 n(k)+1}$ and $y=z$ in (41) and use (54), we obtain $S z=z$. By uniqueness of the fixed point, $z$ is a unique common fixed point of $S$ and $T$.

Again, if $p\left(x_{2 n}, x_{2 n+1}\right)=0$ or $p\left(x_{2 n}, x_{2 n+2}\right)=0 \forall n \geq 0$, then we will show that the mappings $S$ and $T$ have a common fixed point in $X$.

Here, we suppose that $p\left(x_{2 n}, x_{2 n+2}\right)=0 \forall n \geq 0$. Then by Remark 2, $x_{2 n}=x_{2 n+2}$, for all $n \geq 0$. Let $n=k$, and then

$$
x_{2 k}=x_{2 k+2} \quad \forall k \geq 0 .
$$

From (41), we get

$$
\begin{gathered}
\psi\left(p\left(x_{2 k+1}, x_{2 k+2}\right)\right) \\
=\psi\left(p\left(T x_{2 k}, S x_{2 k+1}\right)\right) \\
\leq \varphi\left(\left(\left(p\left(x_{2 k}, S x_{2 k+1}\right)\right)+\left(p\left(T x_{2 k}, x_{2 k+1}\right)\right)\right.\right. \\
\left.\left.+\left(p\left(x_{2 k}, x_{2 k+1}\right)\right)\right)(3)^{-1}\right) \\
-\phi\left(\left(p\left(x_{2 k}, S x_{2 k+1}\right)\right),\left(p\left(T x_{2 k}, x_{2 k+1}\right)\right),\right. \\
\left.\quad\left(p\left(x_{2 k}, x_{2 k+1}\right)\right)\right) .
\end{gathered}
$$

Using $\left(P_{4}\right),\left(P_{1}\right)$, and (57) above, we obtain

$$
\begin{aligned}
0 \leq & (\psi-\varphi) p\left(x_{2 k+1}, x_{2 k+2}\right) \\
\leq & -\phi\left(p\left(x_{2 k}, x_{2 k+2}\right), p\left(x_{2 k+1}, x_{2 k+1}\right), p\left(x_{2 k}, x_{2 k+1}\right)\right) \\
\Longrightarrow & \phi\left(p\left(x_{2 k}, x_{2 k+2}\right), p\left(x_{2 k+1}, x_{2 k+1}\right)\right. \\
& \left.\quad p\left(x_{2 k}, x_{2 k+1}\right)\right)=0 \\
\Longrightarrow & p\left(x_{2 k}, x_{2 k+2}\right)=0, \quad p\left(x_{2 k+1}, x_{2 k+1}\right)=0 \\
& p\left(x_{2 k}, x_{2 k+1}\right)=0 \\
\Longrightarrow & x_{2 k}=x_{2 k+1}=x_{2 k+2} \quad \forall k \geq 0 .
\end{aligned}
$$

Similarly, we can show that

$$
x_{2 k}=x_{2 k+1}=x_{2 k+2}=x_{2 k+3}=\cdots \quad \forall k \geq 0 .
$$

Thus $\left\{x_{n}\right\}$ becomes a constant sequence. So $x_{n}=T x_{n}=S x_{n}$ for all $n \geq 0$. Hence $x_{n}$ is a common fixed point of $T$ and $S$.

Finally, we assume that $p\left(x_{2 n}, x_{2 n+1}\right)=0 \forall n \geq 0$. Then by Remark 2, we have $x_{2 n}=x_{2 n+1} \forall n \geq 0$. Let $n=k$, and then

$$
x_{2 k}=x_{2 k+1} \quad \forall k \geq 0 \text {. }
$$


Using (58), (61), and $\left(P_{4}\right)$ with property of nondecreasing function $\varphi$, we have

$$
\begin{aligned}
0 & \leq(\psi-\varphi) p\left(x_{2 k+1}, x_{2 k+2}\right) \\
& \leq-\phi\left(p\left(x_{2 k}, x_{2 k+2}\right), p\left(x_{2 k+1}, x_{2 k+1}\right), p\left(x_{2 k}, x_{2 k+1}\right)\right) .
\end{aligned}
$$

Using similar property of $\phi$, as used in first case, we have

$$
x_{2 k}=x_{2 k+1}=x_{2 k+2}=x_{2 k+3}=\cdots \quad \forall k \geq 0 .
$$

Thus, $\left\{x_{n}\right\}$ becomes a constant sequence. So $x_{n}=T x_{n}=S x_{n}$. Hence $x_{n}$ is a common fixed point of $T$ and $S$.

Example 19. Let $T, p, \psi, \varphi$, and $\phi$ all be the same as in Example 13 and a self-mapping $S$ on $[0,1]$ defined as $S x=$ $x^{2} / 2+x^{3} / 3$. Then 0 is a unique common fixed point of $S$ and $T$. One can compute the solution similarly as done in Example 13.

Corollary 20. Two self-continuous nondecreasing mappings $S$ and $T$ on a complete partial metric space $(X, p)$, satisfying the condition

$$
\begin{aligned}
\psi(p(T x, S y)) \leq & \psi\left(\frac{p(x, S y)+p(T x, y)+p(x, y)}{3}\right) \\
& -\phi(p(x, S y), p(T x, y), p(x, y))
\end{aligned}
$$

for all $x, y \in X$ and $\psi$ and $\phi$, are the same as in Theorem 18, having a unique common fixed point in $X$.

Corollary 21. In Corollary 20, if partial metric space $(X, p)$ is replaced by usual metric space $(X, d)$, then one gets Theorem 2.3 of [21].

Corollary 22. If one puts $p(x, y)=0$ in (41) and lets $\phi$ : $[0, \infty) \times[0, \infty) \rightarrow[0, \infty)$ be a function, such that $\phi(x, y)=0$ if and only if $x=y=0$, then Theorem 18 reduces to Theorem 2.3 of [13].

\section{Conflict of Interests}

The authors declare that there is no conflict of interests regarding the publication of this paper.

\section{Acknowledgments}

The authors would like to express their deep gratitude to the anonymous learned referee(s) and the editor for their valuable suggestions and constructive comments, which resulted in the subsequent improvement of this research article. Special thanks are due to our great Master and friend academician Professor M. Mursaleen, Editor of the Journal of Function Spaces, for his efforts to send the reports of the paper timely. The authors are also grateful to all the editorial board members and reviewers of esteemed journal, that is, Journal of Function Spaces. The first author Lakshmi Narayan Mishra acknowledges the Ministry of Human Resource
Development, New Delhi, India, for supporting this research article. All the authors carried out the proof of theorems. Each author contributed equally in the development of the paper. Vishnu Narayan Mishra conceived of the study and participated in its design and coordination. The second author Shiv Kant Tiwari is grateful to Ms. Jagrati Bilthare for her valuable suggestions during the preparation of this paper. All the authors read and approved the final version of paper.

\section{References}

[1] M. Frechet, "Sur quelques points du calcul fonctionnel," Rendiconti del Circolo Matematico di Palermo, vol. 22, pp. 1-74, 1906.

[2] B. S. Choudhury, "Unique fixed point theorem for weak Ccontractive mappings," Kathmandu University Journal of Science, Engineering and Technology, vol. 5, no. 1, pp. 6-13, 2009.

[3] D. P. Shukla and S. K. Tiwari, "Unique fixed point theorem for weakly S-contractive mappings," General Mathematics Notes, vol. 4, no. 1, pp. 28-34, 2011.

[4] Deepmala, A study of fixed point theorems for nonlinear contractions and its applications [Ph.D. thesis], Pt. Ravishankar Shukla University, Raipur, India, 2014

[5] Deepmala and H. K. Pathak, "A study on some problems on existence of solutions for nonlinear functional-integral equations," Acta Mathematica Scientia, Series B-English Edition, vol. 33, no. 5, pp. 1305-1313, 2013.

[6] S. K. Chatterjea, "Fixed-point theorems," Comptes Rendus de l'Academie Bulgare des Sciences, vol. 25, pp. 727-730, 1975.

[7] T. Abdeljawad, "Fixed points for generalized weakly contractive mappings in partial metric spaces," Mathematical and Computer Modelling, vol. 54, no. 11-12, pp. 2923-2927, 2011.

[8] V. N. Mishra, M. L. Mittal, and U. Singh, "On best approximation in locally convex space," Varahmihir Journal of Mathematical Sciences India, vol. 6, no. 1, pp. 43-48, 2006.

[9] V. N. Mishra, Some problems on approximations of functions in Banach spaces [Ph.D. thesis], Indian Institute of Technology, Uttarakhand, India, 2007.

[10] V. N. Mishra and L. N. Mishra, "Trigonometric approximation in $L_{p}(p \geq 1)$-spaces," International Journal of Contemporary Mathematical Sciences, vol. 7, pp. 909-918, 2012.

[11] S. G. Matthews, "Partial metric topology", in Proceeding of 8th Summer conference on General Topology and Applications at Queens College, vol. 728, pp. 183-197, Annals of the New York Academy of Sciences, New York, NY, USA, 1994.

[12] S. G. Matthews, "Partial metric topology," Research Report 212, Department of Computer Sciences, University of Warwick, 1992.

[13] C. Chen and C. Zhu, "Fixed point theorems for weakly Ccontractive mappings in partial metric spaces," Fixed Point Theory and Applications, vol. 2013, article 107, 2013.

[14] K. P. Chi, E. Karapınar, and T. D. Thanh, "A generalized contraction principle in partial metric spaces," Mathematical and Computer Modelling, vol. 55, no. 5-6, pp. 1673-1681, 2012.

[15] V. C. Rajik, S. Radenovic, and S. Chauhan, "Common fixed point of generalized weakly contractive maps in partial metric spaces," Acta Mathematica Scientia, vol. 34, no. 4, pp. 1345-1356, 2014.

[16] H. Aydi, S. Hadj Amor, and E. Karapınar, "Berinde-type generalized contractions on partial metric spaces," Abstract and Applied Analysis, vol. 2013, Article ID 312479, 10 pages, 2013. 
[17] E. Karapinar and I. M. Erhan, "Fixed point theorems for operators on partial metric spaces," Applied Mathematics Letters, vol. 24, no. 11, pp. 1894-1899, 2011.

[18] N. Shobkolaei, S. M. Vaezpour, and S. Sdghi, "A common fixed point theorem on ordered partial metric spaces," Journal of Basic and Applied Scientific Research, vol. 1, pp. 3433-3439, 2011.

[19] E. Karapinar and I. S. Yuce, "Fixed point theory for cyclic generalized weak $\varphi$-contraction on partial metric spaces," Abstract and Applied Analysis, vol. 2012, Article ID 491542, 12 pages, 2012.

[20] M. S. Khan, M. Swaleh, and S. Sessa, "Fixed point theorems by altering distances between the points," Bulletin of the Australian Mathematical Society, vol. 30, no. 1, pp. 1-9, 1984.

[21] W. Shatanawi, "Fixed point theorems for nonlinear weakly C-contractive mappings in metric spaces," Mathematical and Computer Modelling, vol. 54, no. 11-12, pp. 2816-2826, 2011. 


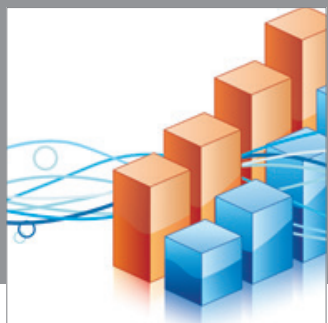

Advances in

Operations Research

mansans

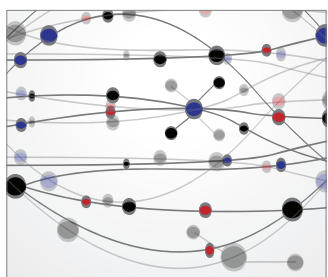

The Scientific World Journal
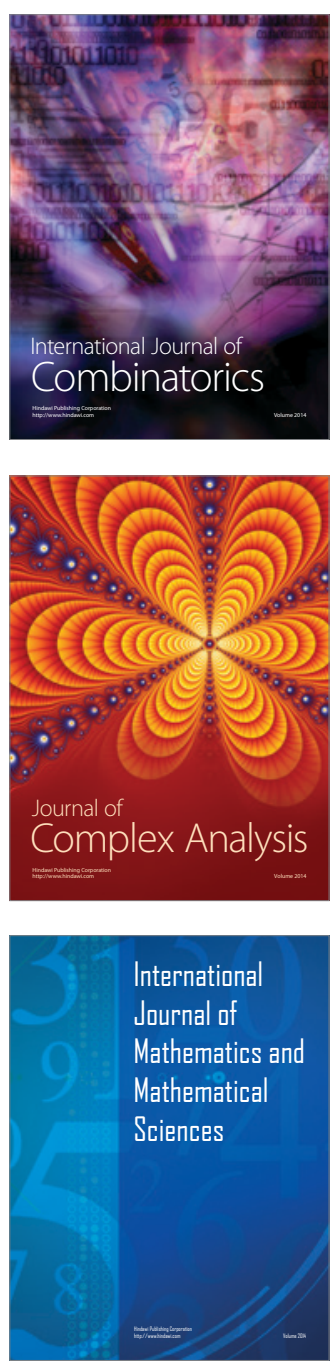
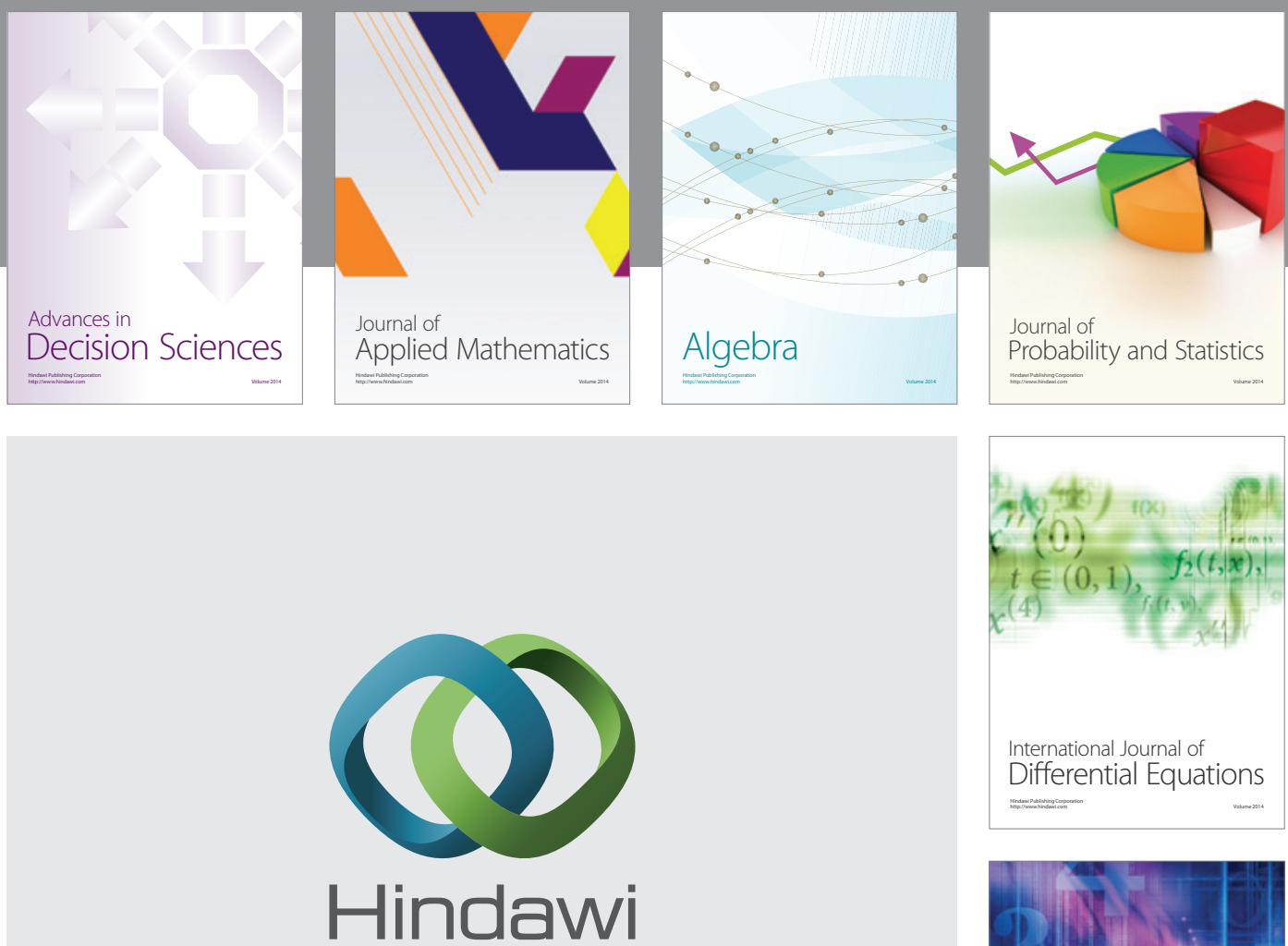

Submit your manuscripts at http://www.hindawi.com
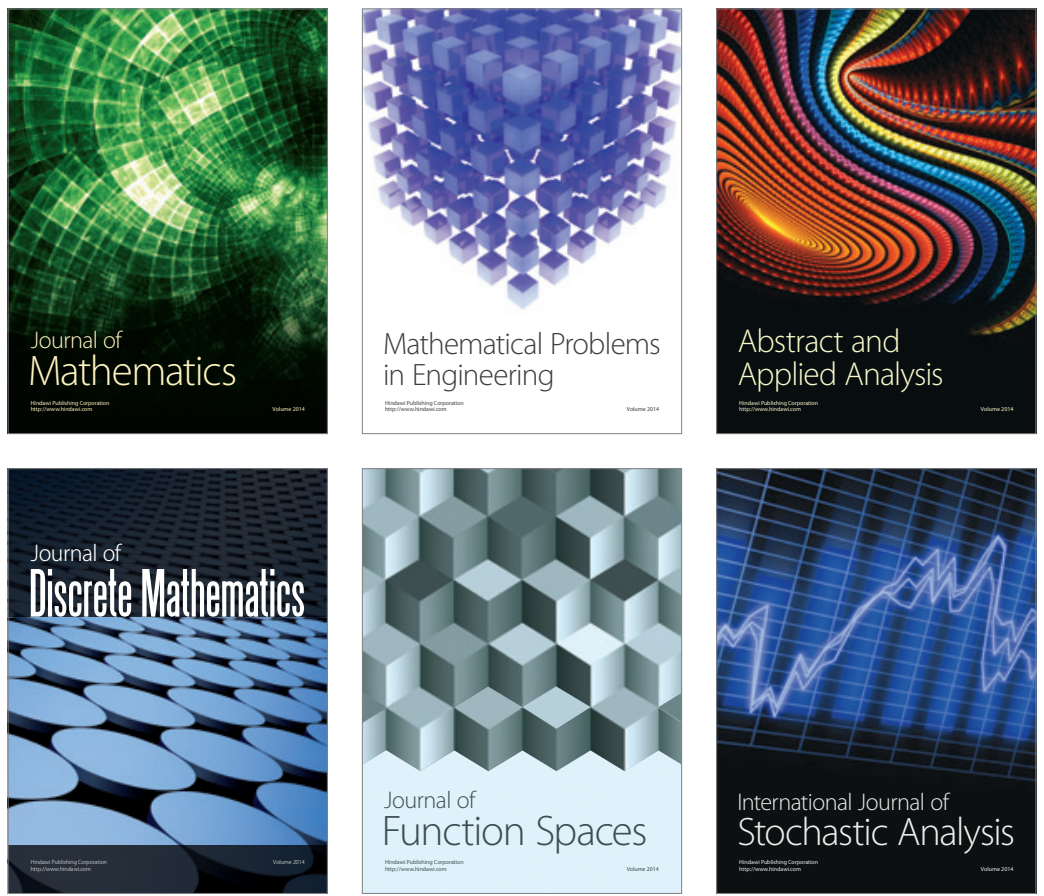

Journal of

Function Spaces

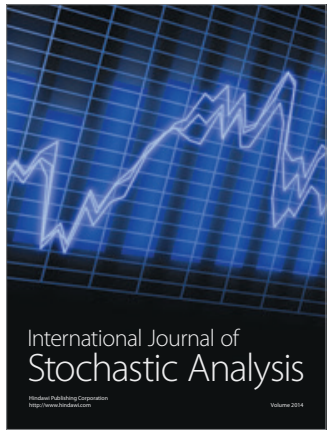

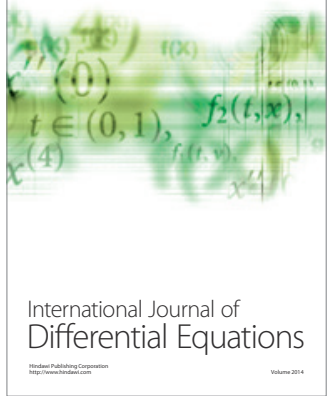
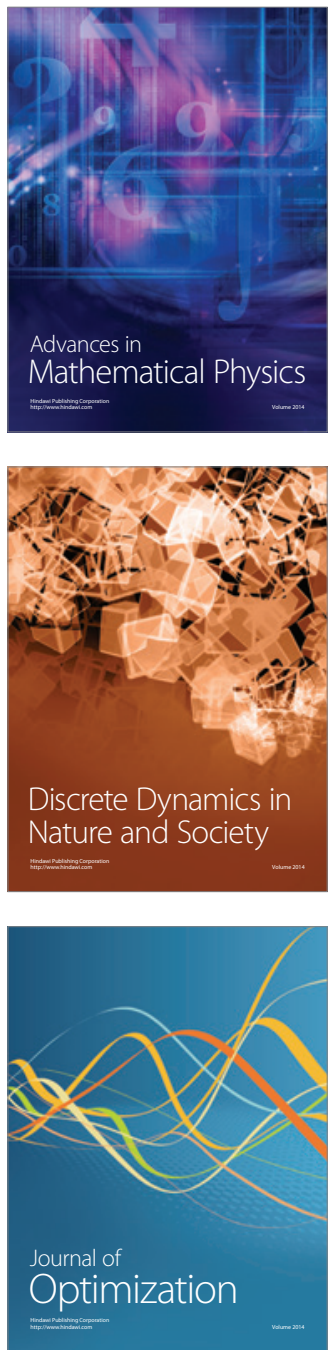